\title{
Elements of circular technologies in aquaculture on the waters of energy facilities
}

\author{
Marina Kalaida ${ }^{1}$, Madina Khamitova $^{1}$, Andrey Kalaida ${ }^{2}$, Svetlana Borisova ${ }^{1, *}$, and Valeria Babikova ${ }^{1}$ \\ ${ }^{1}$ FSBEI HE "Kazan State Power Engineering University", Department of "Aquatic Bioresources and Aquaculture", Kazan, Russia \\ ${ }^{2}$ LLC "Biosphere - Fish"Kazan, Russia
}

\begin{abstract}
The elements of circular technologies in aquaculture on various energy waters are considered. The development of forms of aquaculture from pasture to industrial with an increase in the share of circular technologies is shown. It is noted that the use of cage fish farming on warm waste waters of energy facilities is complicated by eutrophication at high fish stocking densities and the peculiarities of temperature and hydrochemical regimes. The necessity of selection of new aquaculture objects with a fast growth rate, thermophilic and not demanding to the oxygen content in water is noted: a promising object of cultivation in warm waters is the African clary catfish (Clarias gariepinus). Possibilities of including other representatives of catfish - shill catfish (Pangasius) are considered. The results of experimental cultivation of spicy vegetable crops on waste products of crucian carp and clary catfish are presented. The analysis of own data and data of foreign sources is carried out. The dependence of the growth of valuable plant species on the type of fish in aquaponics is shown. Aquaculture and aquaponics as specific components of the modern agricultural sector in the development are focused on industrial production technologies using circular technologies for the efficient use of resources.
\end{abstract}

\section{Introduction}

Aquaculture includes all forms of aquatic animals and plants growing in different types of water bodies with different environmental characteristics. Aquaculture has the same goal as agriculture: to increase food production above levels that are naturally produced. The main challenge for aquaculture development today is to increase the share of global aquatic food production [1].

The share of fish products destined for human consumption is expected to continue to grow and will reach about $89 \%$ by 2030 , consumption of edible fish in all regions and sub-regions will be higher than in 2018 [1].

Aquaculture farms use regional water resources as the basis of their development. At the same time, the level of development of the industrial potential of the territory is determined by the development of energy. At the same time, for energy facilities, the main resource part, as well as for aquaculture, is high quality water. The development of the Middle Volga region is closely related to the regulation of the river Volga and its transformation into a cascade of reservoirs. Opinions were expressed about the inadmissibility of the construction of waterworks on the lower Volga, since the conditions for the spawning of the most valuable sturgeon fish would radically change [2]. The Volga River in the global catch of fish in the main river basins in the world determines the share of the total catch $0.28 \%$, and the Caspian Sea - 0.76\% [1].
To increase food production in the recent period, innovative biotechnological methods for the production of fish products have been actively used, at the same time using circular biotechnologies, involving waste from various industries in the process, which is important from the standpoint of preserving the quality of the environment and reducing the environmental load on the territory.

The purpose of our study is to consider the elements of circular technologies in aquaculture of the modern Middle Volga region.

\section{Material and research technique}

In the course of the work, an analysis was carried out of the results of our own research and literature data on various areas of aquaculture development using circular elements, statistical information on catches and the amount of fish production. When analyzing the biological characteristics of aquaculture objects and hydrobionts of the periphyton in biofilters of industrial fish-breeding installations, traditional methods of data collection, processing and analysis were used. The materials on the use of aquaponics, the periphyton community of treatment facilities, and the cultivation of thermophilic aquaculture species are analyzed and summarized. The analysis used materials on the objects contained in the recirculating aquaculture systems of the Department of "Water bioresources and aquaculture" FSBEI HE KSPEU since 2016.

\footnotetext{
* Corresponding author: svetlana-zag@,bk.ru
} 


\section{Results and discussion}

The development of circular technologies in aquaculture in the Middle Volga region is consistent with global trends.

Global aquaculture production has grown by $7.5 \%$ per year since 1970, reflecting the importance of this sector as a factor in global food security [1].

During this period, in the Middle Volga region, the main focus of work is pasture aquaculture in the Kuibyshev reservoir with separate releases of valuable fish species. In connection with the Food Program in the 1980s, the warm waters of the cooling reservoir of the Zainsk Power Station are actively used for fish production. Many modern power plants use cooling towers and cooling ponds for cooling. At the same time, the consumption of water cooling the turbine condensers is approximately $50 \mathrm{~m}^{3} / \mathrm{s}$ per $1000 \mathrm{MW}$ of electrical power, and its temperature should not increase by more than $10^{\circ} \mathrm{C}$. To remove such an amount of heat, it is necessary to have a surface area of the cooling reservoir of $10-12 \mathrm{~km}^{2}$ per $1000 \mathrm{MW}$, while the amount of water going for evaporation reaches $30 \bullet 106 \mathrm{~m}^{3} /$ year [3].

The main obstacle to using the heat that is removed by the cooling water is its low temperature potential. There are areas of the national economy where lowgrade heat can be efficiently utilized: the "waste heat" of power plants can be used in fish farming, which together forms an energy-biological complex.

The reservoir - cooler of the Zainsk Power Station was used for feeding herbivorous fish of the Far Eastern complex white silver carp and bighead carp and their hybrids. The introduction in different years was carried out by individuals of different ages of silver carp: larvae, underyearlings, yearlings, two- and even three-year-olds. In 1995-1997, their reserves in the Zainsk reservoir were estimated at 20-25 tons (about 3.5-4 thousand specimens). In 1996, in catches with large-mesh nets (100-120 mm), $71 \%$ of fish were silver carps of the generation born in $1989,21 \%$ - in 1987 , and $4 \%$ were found in fish born in 1984 and 1985. By the age of 8-9 years in the conditions of the cooling pond Zainsk Power Station, silver carps practically reach their maximum size - they had a body length of about $1 \mathrm{~m}$. Individuals of 7 years of age turned out to be suitable for the conditions of reproduction. In May, they were at the 4th stage of gonad maturity and were suitable for the tasks of artificial reproduction. The absolute fecundity of females varied from 646.8 to 1800 thousand eggs, which in ovaries were represented by two size groups with a diameter of $4-8$ and $12-18 \mathrm{~mm}$. The mass of testes in males at the 4th stage of gonad maturity varied from 40 to $70 \mathrm{~g}$.

As an element of the circular technology, the warm waste waters of the power station were used not only as a basis for pasture aquaculture, but also as a base for placing a cage line for growing marketable fish. Cooling ponds are water bodies adapted to remove a significant amount of heat generated during technological processes.

An increase in the scale and intensification of production, on the one hand, leads to an increase in profitability, and on the other hand, intensive exploitation of aquatic ecosystems of reservoirs affects their sustainability. This manifested itself in the Cirata and Saguling reservoirs, where the number of cages far exceeded the potential capacity of the ecological systems of these two reservoirs [4]. As a result, this has led to fish mortality, social conflict and increased susceptibility of fish to disease, the most recent event was the mass mortality of common carp infected with the koi herpes virus (KHV) [5]. Another striking example is the mortality of fish under the conditions of an abnormally hot temperature in 2016 in the Middle Volga region, which led to deadly conditions in the area of the cage line on the cooling pond of the Zainsk Power Plant, when the mortality of fish overnight led to the loss of 170 tons of carp in the cages.

The problem arises of selecting objects for growing in conditions that turned out to be unacceptable for fish in the middle lane, for example, for carp in the cage farm of Zainsk Power Plant - growing at a water temperature of more than $30^{\circ} \mathrm{C}$ and a low oxygen content - up to 5 $\mathrm{mg} / \mathrm{l}$.

In the $70 \mathrm{~s}$ of the twentieth century, various catfish acclimatizers - were involved in aquaculture in Russia. In 1972, channel catfish - Ictalurus punctatus Raf, the main objects of commercial fish farming in America and the favorite objects of sport fishing, were brought to Russia. These are thermophilic objects with little demand for oxygen content in water. Methods of reproduction of channel catfish were developed: pond, cage and aquarium. Channel catfish were actively used for cultivation in cage farms on warm waters of energy facilities [6]. Due to the change in the economic situation in the country, their introduction into the Middle Volga region was not carried out.

At the present stage of full understanding of the need to actively develop intensive forms of production of aquaculture products to ensure not only the health of the population, but also food security, the African clarius catfish (Clarias gariepinus) is a promising object of cultivation in warm waters. Work on its fishery development began in Russia in 1996 [7]. Compared to Clarias gariepinus, the Nile Clarias (Clarias anguillaris) is able to withstand even higher temperatures and is even more unpretentious in diet. Claria have a high rate of mass accumulation: from larvae to marketable weight of $1.2 \mathrm{~kg}$, the growing time is six months in warm waters, and are resistant to diseases.

Perspective objects of cage culture in warm waters are also other representatives of catfish - shill catfish Siamese pangasius (Pangasius sutchi, Fowler, 1937), and Pangasius hypophthalmus from the Pangasiidae family, which are called shark catfish. Pangasianodon hypophthalmus is one of the largest aquaculture species produced in the world and accounted for $4.3 \%$ of the 2018 catches [1]. They can be used for warm water cage culture in energy facilities.

With a number of advantages, the cage form of fish farming faces a serious environmental problem. High stocking densities of fish grown in cage farms and intensive feeding with artificial feed increase the amount 
of organic matter in the reservoir where the farms are located, that is, they contribute to its eutrophication.

In the recent period, in order to meet the growing consumer demand for fish throughout the world, industrial aquaculture is actively developing on the basis of recirculating aquaculture systems (RAS). It allows you to obtain a significant yield of fish products per unit area or volume: for clary catfish up to $300 \mathrm{~kg} / \mathrm{m}^{3}$ and more. Due to the expansion of biotechnology, aquatic organisms can also be grown in RAS, for example, the Australian red claw crayfish Cherax quadricarinatus (Von Martens, 1868) [8].

Recirculation systems in aquaculture (RAS) are complex in composition, including fish farming areas and life support areas. This makes it possible to reuse one of the most important resources of the planet - water.

To ensure the required water quality in the RAS, biofilters are used, in which hydrobiocenoses are formed capable of purifying the waters in the system. Feed residues and faeces place an organic load on the biological filters. Studies conducted by scientists [9] show that oligochaete worms play an important role in the self-purification of polluted waters. A number of oligochaete species can feed on organic waste such as sewage sludge and cattle excrement. Some of the waste from fish and feed dissolves and needs to be decomposed or converted into harmless substances. Special attention is paid to nitrogen-containing waste. Sizing of biological filters is based on the expected load for organic and nitrogen compounds. The study of the features of hydrobiocenoses of biofilters allows one to assess the quality of water purification. The indicator group is the periphyton, which forms on the elements of the biofilter loading.

To study the biocenosis, fouling plates were used [10], which were viewed weekly. Further analysis is carried out by microscopying under a coverslip. Aquatic organisms were determined alive according to tables and figures according to [10].

The study revealed 32 species and forms of organisms in the periphyton of the biofilter of the sturgeon fish hatchery, and in the experimental RAS of the Department of Aquatic Bioresources and Aquaculture of the KSPEU while keeping different aquaculture objects in the basins - 22 species and forms of periphyton organisms.

Plant flagellates (Phytomastigophorea) are represented in the periphyton of the biofilter of the sturgeon plant by the following forms: Ceratium hirudinella (frequency of occurrence 50\%), Chilomonas oblonga (25\%), Trachelomonas hispida (25\%). Of the amoebas, Polychaos fasciculatum was found (25\%). In the periphyton of the biofilter, there were testaceal rhizomes (Testacealobosia), ciliates (Ciliophora), among which Peritricha were widely represented. Planaria, nematodes, rotifers were also noted. Oligochaetes were represented by 2 species: Aelosoma hemprichi (100\%) and Chaetogaster diaphanus (75\%).

The assessment showed that Aelosoma hemprichi from oligochaetes can be attributed to the dominant forms in the periphyton of the biofilter. The subdominants include: Planaria sp., from peritrichous -
Euplotes affinis, Vorticella picta typical, Aspidisca costata, from rotifers - Collotheca sp., Encentrum putorius $z$ from shell rhizopods - Arcella sp., Nematodes, from oligochaetes - Chaetogaster diaphanus. The rest of the periphyton are subdominants of the first order.

The indices of species similarity in the studied biocenoses of biofilters were: Serensen index - 0.74, Jaccard index - 0.58, Mountford index - 0.121.

When assessing the quality of water by the composition of the biocenosis of biofilters, a hydrobiological analysis of the indicator values of organisms was carried out (Fig. 1).

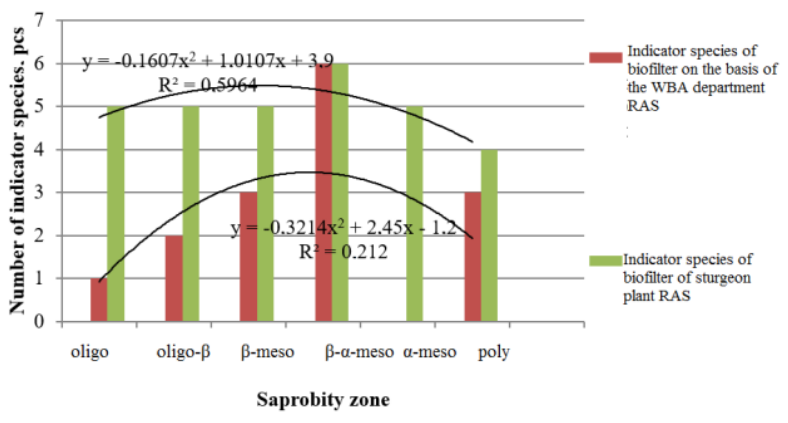

Fig. 1. Ratio of indicator species of different saprobity zones.

By the number of indicator species in the RAS biofilter of the department with different species of aquatic organisms in the basins, organisms characteristic of the $\beta$ - $\alpha$-mesosaprobic zone prevailed, such as Hemiophrys pleurosigma (Stokes, 1884), Epistylis urceolata (Stiller, 1933), Euplotes affinis (Dujardin, 1841), Aeolosoma hemprichi (Ehrenberg 1828). The biofilter of the sturgeon plant was also dominated by organisms characteristic of the $\beta$ - $\alpha$-mesosaprobic zone, such as Actinophrys sol (Ehrenberg, 1830), Hemiophrys pleurosigma (Stokes, 1884), Epistylis urceolata (Stiller, 1933), Euplotes affinis (Dujardin, 1841), Tokophrya mollis (Bütschli, 1889), Aeolosoma hemprichi (Ehrenberg 1828).

This study is also interesting in that it demonstrates the complication of aquatic hydrobiocenosis organized for keeping aquaculture objects in an artificially created system on artificial feed. The emerging complex hydrobiocenosis of fouling organisms is a set of consumers of a different order. Thus, a fish breeding system with elements of circular technologies becomes similar to a natural ecosystem.

Further development of the circular approach to the operation of RAS is that not only water is used repeatedly, but also fish waste products serve as a source of nutrients for other objects of cultivation, for example, in aquaponics.

Aquaponics is based on the use of waste products from aquaculture objects as a nutrient medium for plants in an aquaponic installation. In the course of growth, plants consume the metabolic products of living organisms they need - chemical substances (nitrogenous, potassium, phosphorus compounds, carbon dioxide, etc.), dissolved in water, and at the same time, naturally purify and enrich it with oxygen. In the process of plant 
mass production, the need for the use of chemical fertilizers, as is done in hydroponics, is eliminated. Thus, aquaponics is a circular biotechnology for the reuse of not only waste water, but also fish metabolites.

Aquaponics is actively developing in the Netherlands, where, within the EcoFutura project, a technology has been developed for growing tomatoes in winter in an aquapon installation. In many cities in the USA, Canada and Europe, aquaponics is common as a form of urban agriculture. Entrepreneurs and farmers build greenhouses in the city center, occupy warehouses or rooftops. American engineers and biologists have developed the Aquaponics USA farms, consisting of two containers for fish and for plants, pumps and pipes. In Lithuania, the company JSC "Aquaponica" is engaged in the cultivation of African catfish and various plants, such as lettuce, spinach, spicy plants (dill, parsley, calendula, basil). Swiss company Urban Farmers has developed containers consisting of an aquarium and a mini garden $[11,12]$.

The results of experimental cultivation of vegetable basil and lettuce in a model aquaponic setup showed that they grew well on fish metabolites in winter. Salad on metabolites of clariate catfish had higher rates of weight gain.

In aquaponics, good growth of C. gariepinus was described in combination with water spinach (Ipomoea aquatica), basil (Ocimum basilicum) [13], lettuce (Lactuca sativa), cucumber (Cucumis sativus), and tomato (Solanum lycopersicum). However, the growth of basil and parsley (Petroselinum crispum) was reduced in combination with $\mathrm{C}$. gariepinus compared with Nile tilapia (O. niloticus) [14]. Thus, the choice of fish species influences plant growth [15].

Thus, aquaponics as a circular element of aquaculture can be used in combined biotechnologies. By using resources more efficiently, aquaponics can support economic development, food security and nutrition, FAO says, and complement the global food supply challenge.

\section{Conclusion}

Aquaculture and aquaponics as specific components of the modern agricultural sector in the development are focused on industrial production technologies using circular technologies for the efficient use of resources. The main task of production is to create a synergistic effect when integrating food production systems, reducing water resources usage, reducing pollution, increasing production efficiency.

A more efficient use of resources is realized when using industrial forms of fish farming in warm waters, including energy facilities.

When choosing forms of aquaculture, it is necessary to carry out work on the selection of cultivation objects. In modern conditions, the most successful object for growing in warm waters at high stocking densities are Clarias gariepinus catfish.

Recirculation systems in aquaculture (RAS) are complex in composition, including fish farming areas and life support areas. They are the concentrators of circular technologies: they make it possible to repeatedly use one of the most important resources of the planet water, to use artificial feed when feeding fish, to create aquaponic complexes. The placement of production facilities in closed rooms allows for efficient year-round production, regardless of climatic conditions, close to the urban environment. Thus, additional territories with a low productive status are involved in agricultural production.

The studies have revealed the diversity and complexity of biofilter biosystems in recirculating installations and have shown the effectiveness of growing spicy vegetable crops in aquaponics.

The use of circular elements in modern aquaculture makes it possible to increase the environmental friendliness of industrial production and reduce the load on natural ecosystems.

\section{References}

1. Food and Agriculture Organization of the United Nations (2018) The State of World Fisheries and Aquaculture Available at: http://aquacultura.org/upload/files/pdf/ library/fao (accessed: 20.02.2020)

2. A.B. Avakyan, Volga in the past, present and future (M.: "Ecopress-ZM", 20, 1998)

3. A.M. Vasiliev, Development of greenhouses, subject to the use of the potential of energy generating enterprises, Scientific journal of the Russian Research Institute of Melioration Problems, 2, 48-56 (2011)

4. N.W. Abery, F. Sukadi, A.A. Budhiman, E.S. Kartamihardja, S. Koeshendrajana, Buddhiman and De Silva, S.S. Fisheries and cage culture of three reservoirs in West Java, Indonesia; a case study of ambitious developments and resulting interactions, Fish. Manage. Ecol., 12, 315-330 (2005)

5. M.G. Bondad-Reantaso, Trans-boundary aquatic animal diseases: focus on koi herpes virus (KHV), Aquaculture Asia, 9, 24-28 (2004)

6. Fish-biological standards of fish growing on warm waste waters of thermal power plants and nuclear power plants (M: VNIIPRKH, 34, 1985)

7. V.A. Vlasov, Results of rearing African catfish under various conditions of feeding and housing, News of TSKHA, 3, 136-146 (2009)

8. M.L Kalayda, L.N. Sadykova, Prospects for the cultivation of Australian red claw crayfish Cherax quadricarinatus on warm waters of energy facilities, IOP Conf. Ser.: Earth Environ. Sci., 288, 012048 (2019) DOI: $10.1088 / 1755$ 1315/288/1/012048

9. C.H. Ratsak, J. Verkuijlen, Sludge reduction by predatory activity of aquatic oligochaetes in wastewater treatment plants: Science or fiction?, A review, Hydrobiologia, 564, 197-211 (2006) 
10. L.A. Kutikova, Fauna of aerotanks (Atlas) (L.: Science, 264, 1984)

11. A. Graber, R. Junge, Desalination, Aquaponics systems: Nutrient recycling from fish wastewater by vegetable production, Desalination, 246, 147156 (2009)

12. T. Duncan, Aquaponics floating biofilter grows rice on fish ponds [Electronic resource] Available at: http:/www.aquabiofilter.com/ (accessed: 20.12.2020)

13. H.W. Palm, K. Bissa, U. Knaus, Significant factors affecting the economic sustainability of closed aquaponic systems, Part II: Fish and plant growth, AACL Bioflux, 7, 162-175 (2014)

14. U. Knaus, H.W. Palm, Effects of fish biology on ebb and flow aquaponical cultured herbs in northern Germany, Mecklenburg Western Pomerania, Aquaculture, 466, 51-63 (2017)

15. U. Knaus, L.C. Wenzel, S. Appelbaum, H.W. Palm, Aquaponics (sl) Production of peppermint (Mentha spicata) with African catfish (Clarias gariepinus) in Northern Germany, Sustainability, «Sustainable development», 12 (20), 8717 (2020) 